\title{
Registros de um olhar pelo sul da Etiópia
}

DOI

http://dx.doi.org/10.11606/ 2179-0892.ra.2017.141745

\section{Sylvia Caiuby Novaes}

- Universidade de São Paulo / São Paulo, SP, Brasil

\scaiuby@usp.br

Imagens são sempre construídas, a partir do ol har que as registra. As que aqui apresento foram captadas no sul da Etiópia, em viagens que fiz a esse país em 2005, 2013 e 2017. Meu objetivo é contrapor essas imagens àquela que as pessoas têm em mente quando pensam nesse país, imagem que se cristalizou após um período de fome entre 1983-1985 em que morreram cerca de um milhão de pessoas.

Único país africano que não foi colônia, a Etiópia é densamente povoada. Com área de 1.087.795 quilômetros quadrados (comparável ao tamanho da Bolívia, que tem 11 milhões de habitantes; um pouco menor que o estado do Pará, com 8 milhões de habitantes), é o país que tem a segunda maior população africana-102 milhões de habitantes. Apesar de ser uma das economias que mais cresce no mundo, seu PIB é dos mais baixos.

A Etiópia, com suas paisagens muito diversificadas, surpreendentes mesmo, encanta o olhar. Plantações, áreas montanhosas, campos e desertos fazem parte desse cenário Esse país multilíngue, com mais de 80 grupos etnolinguísticos, apresenta uma diversidade e uma riqueza cultural igualmente impressionantes. A variedade de estilos de casas, rodeadas por pequenas plantações e algum rebanho, a enorme quantidade de cereais cultivados em pequenos campos, os mercados abertos em que as pessoas se reúnem diariamente são aspectos recorrentes da paisagem etíope. É às margens desses mercados que podem ser encontrados os costureiros e barbeiros. A urbanização é fenômeno relativamente recente e é apenas nas cidades que a miséria, tão propalada na imagem que se construiu deste país, pode ser percebida. São poucas as cidades, mas muitos os vilarejos, onde não há muitas diferenças entre a loja e a rua. 
Etnólogos têm, provavelmente, outros parâmetros para a percepção de riqueza e pobreza. Um olhar que busca não se deter exclusivamente naquilo que o Ocidente define como progresso e desenvolvimento. Para esses a Etiópia certamente encanta.

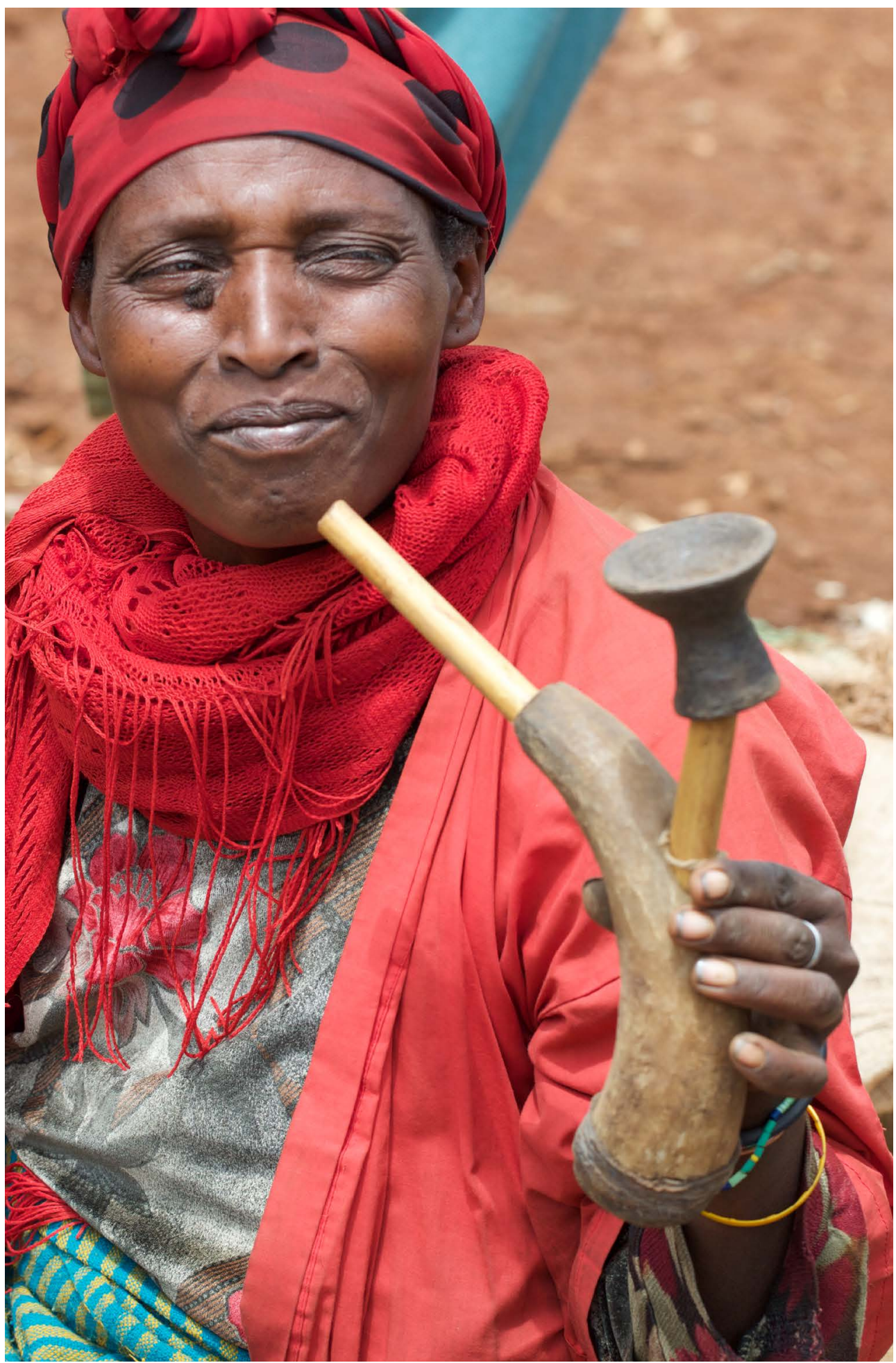



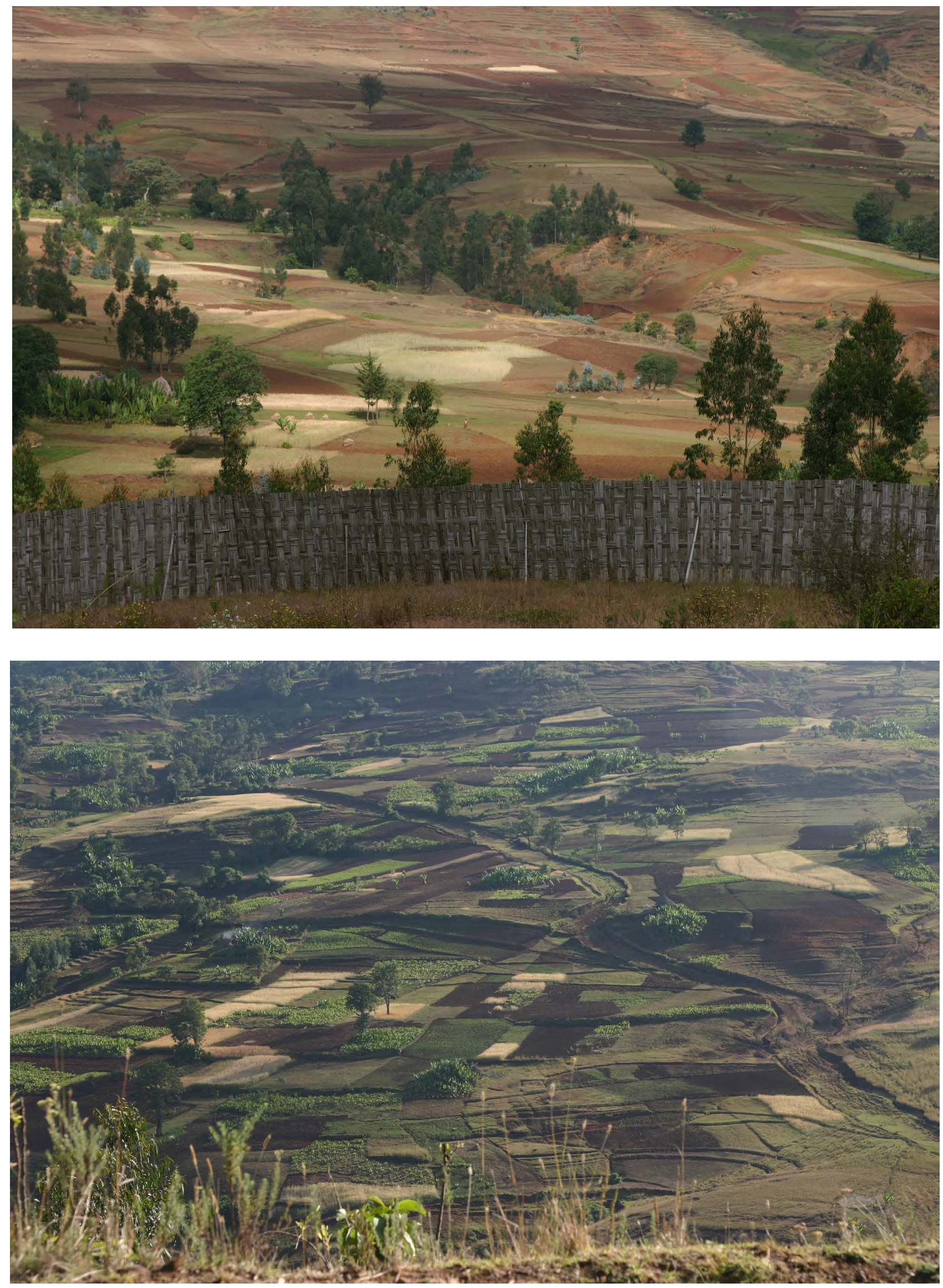

Rev. antropol. (São Paulo, Online) | v. 60 n. 3: 163-180 | USP, 2017 

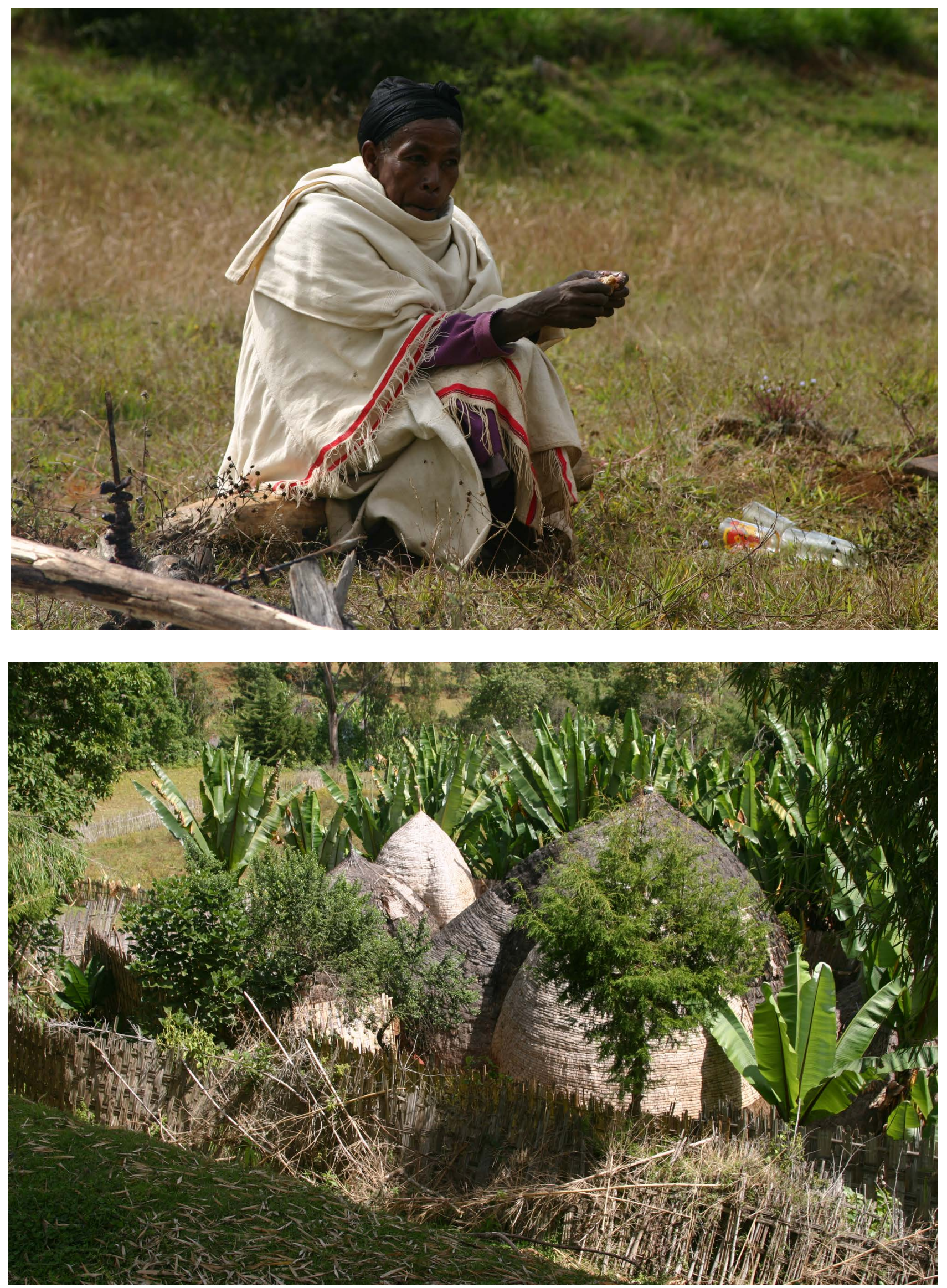

Rev. antropol. (São Paulo, Online) | v. 60 n. 3: 163-180 | USP, 2017 

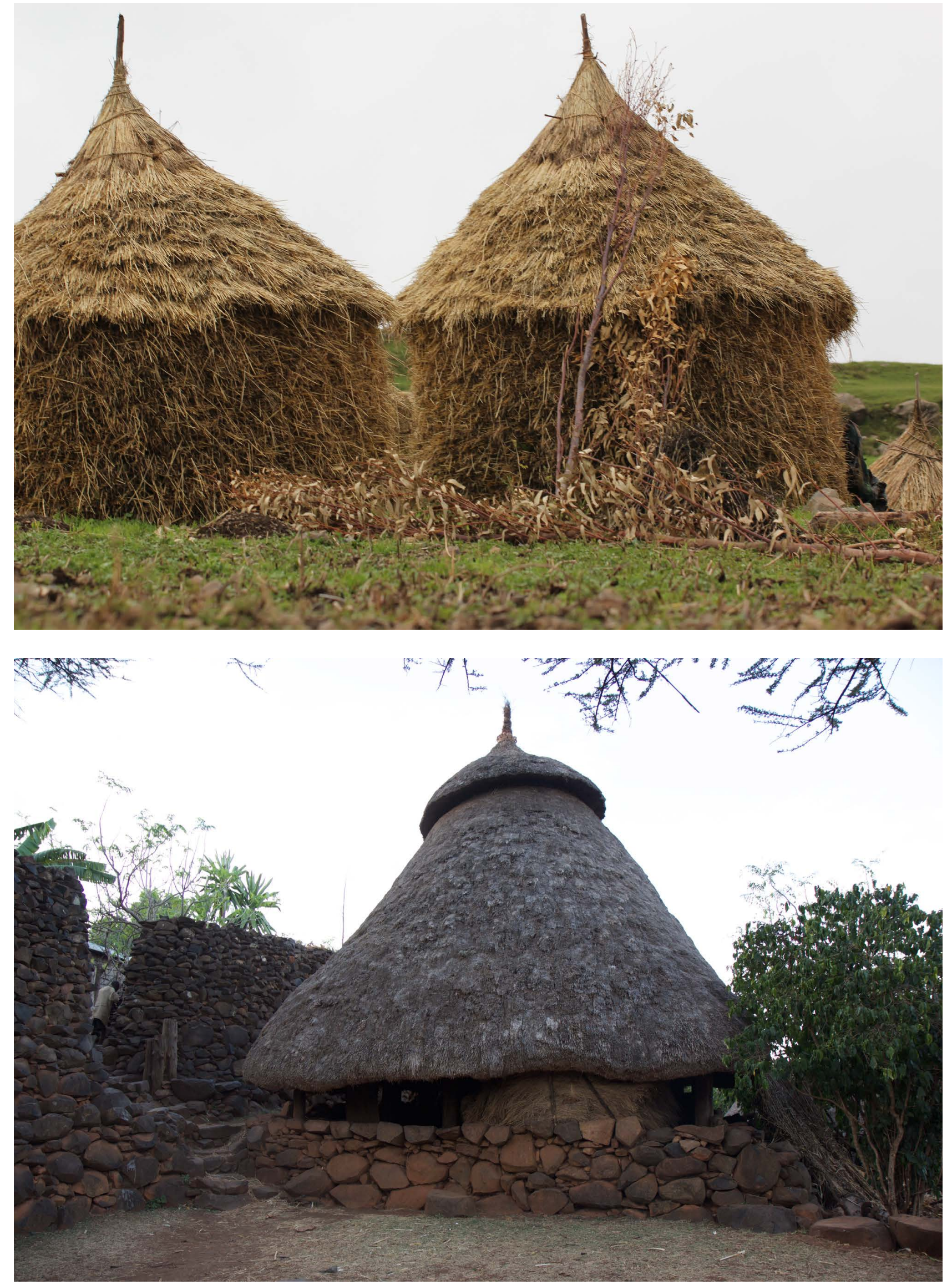

Rev. antropol. (São Paulo, Online) | v. 60 n. 3: 163-180 | USP, 2017 

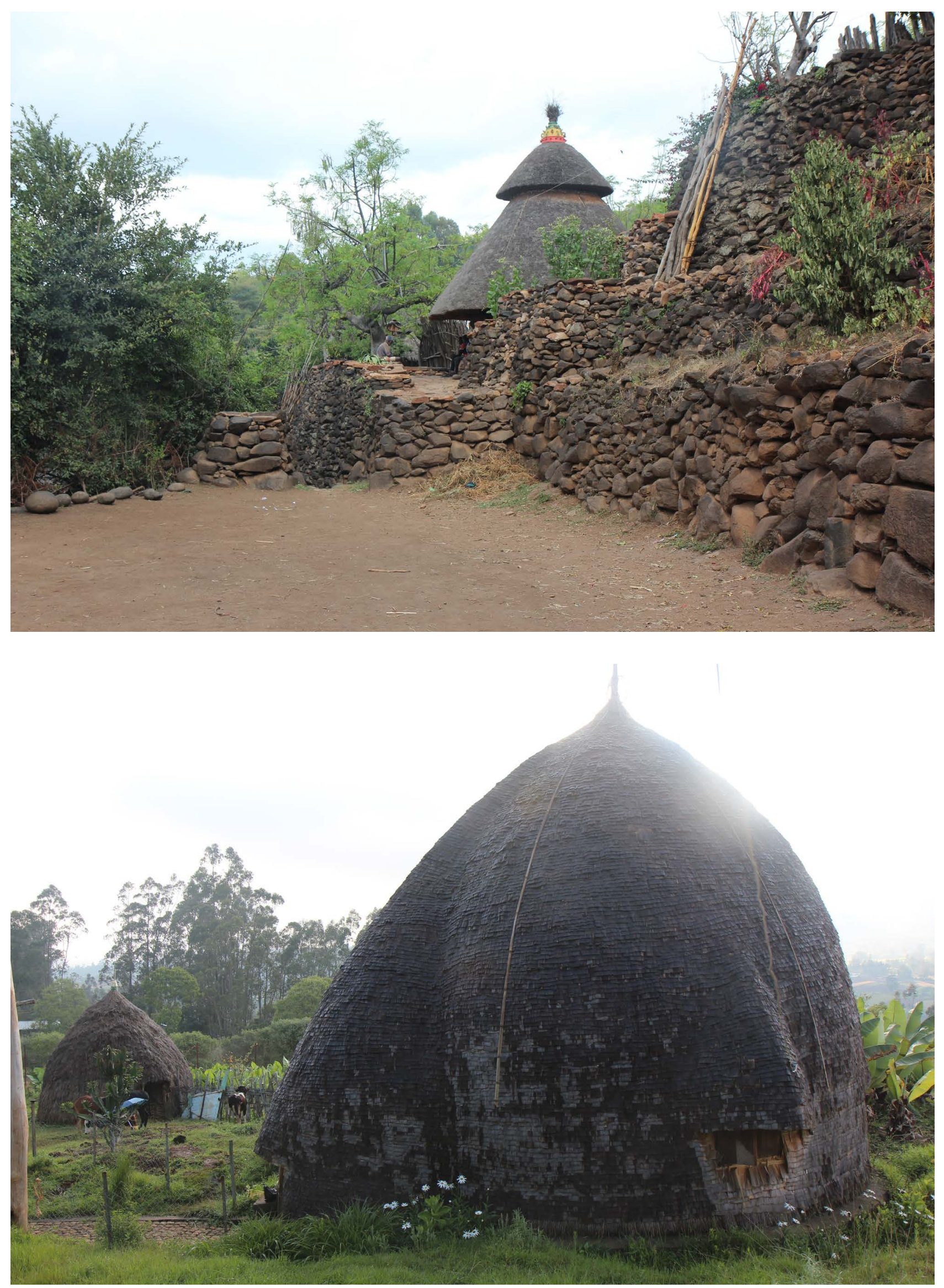

Rev. antropol. (São Paulo, Online) | v. 60 n. 3: 163-180 | USP, 2017 

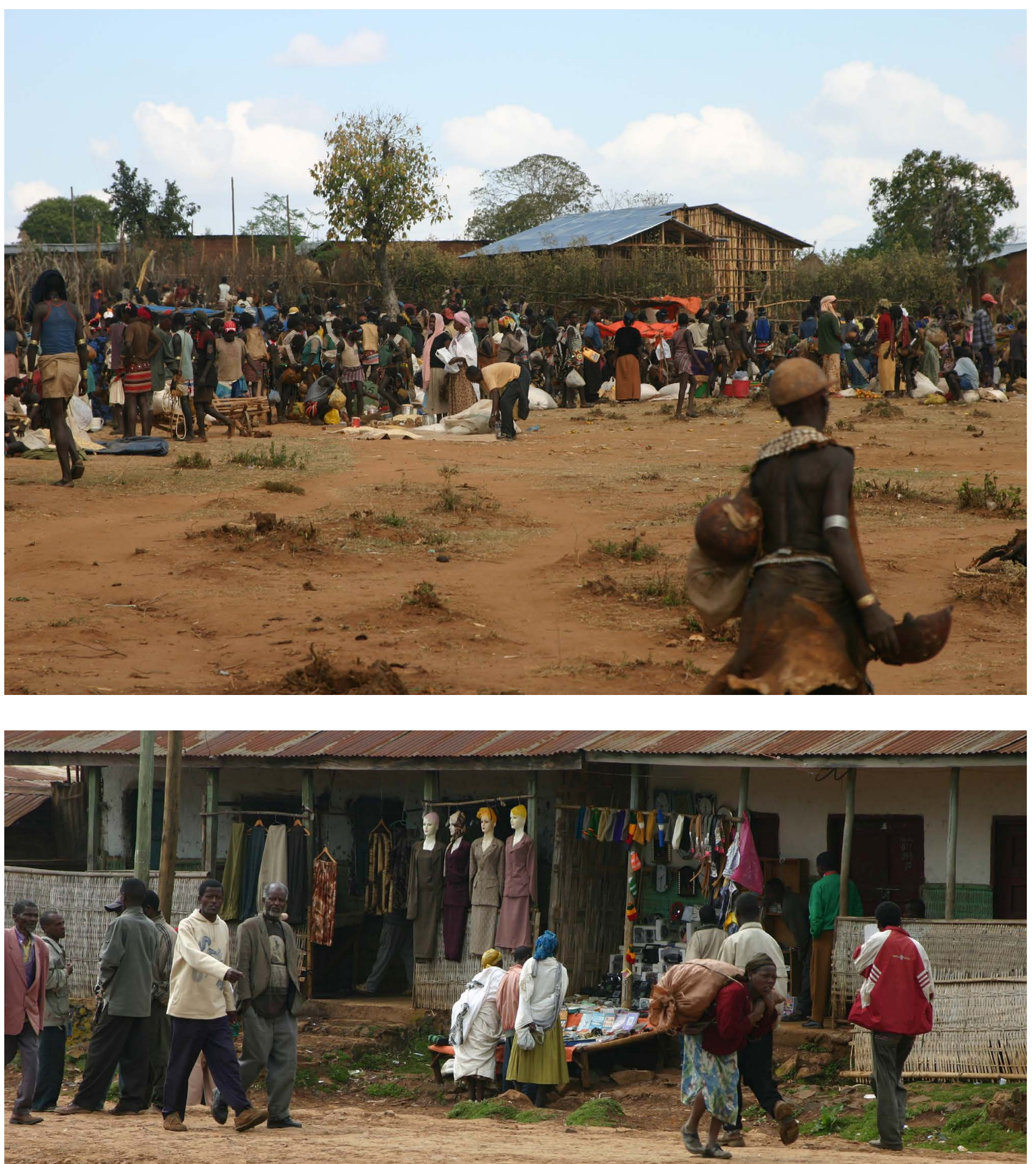

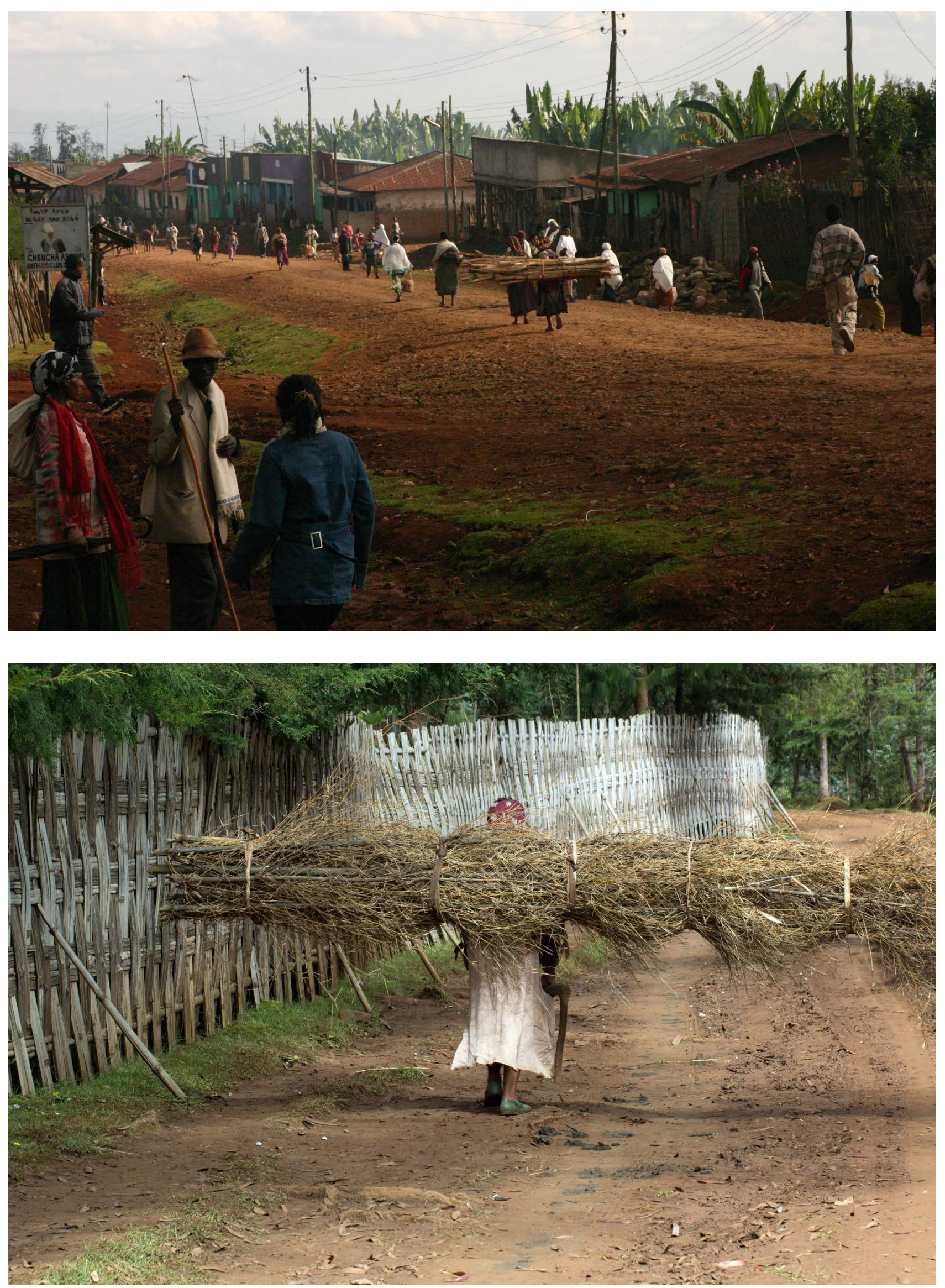

Rev. antropol. (São Paulo, Online) | v. 60 n. 3: 163-180 | USP, 2017 


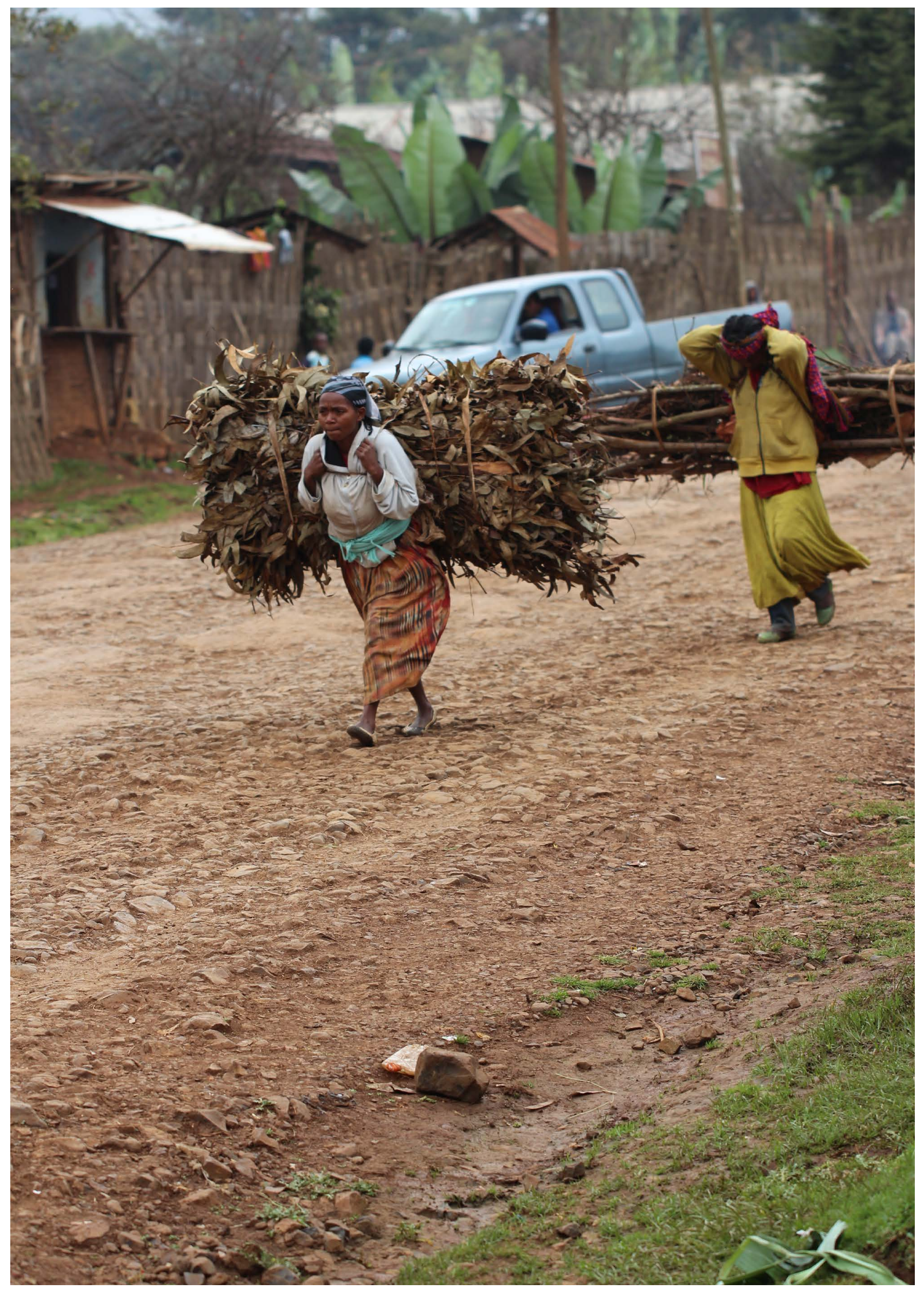

Rev. antropol. (São Paulo, Online) | v. 60 n. 3: 163-180 | USP, 2017 

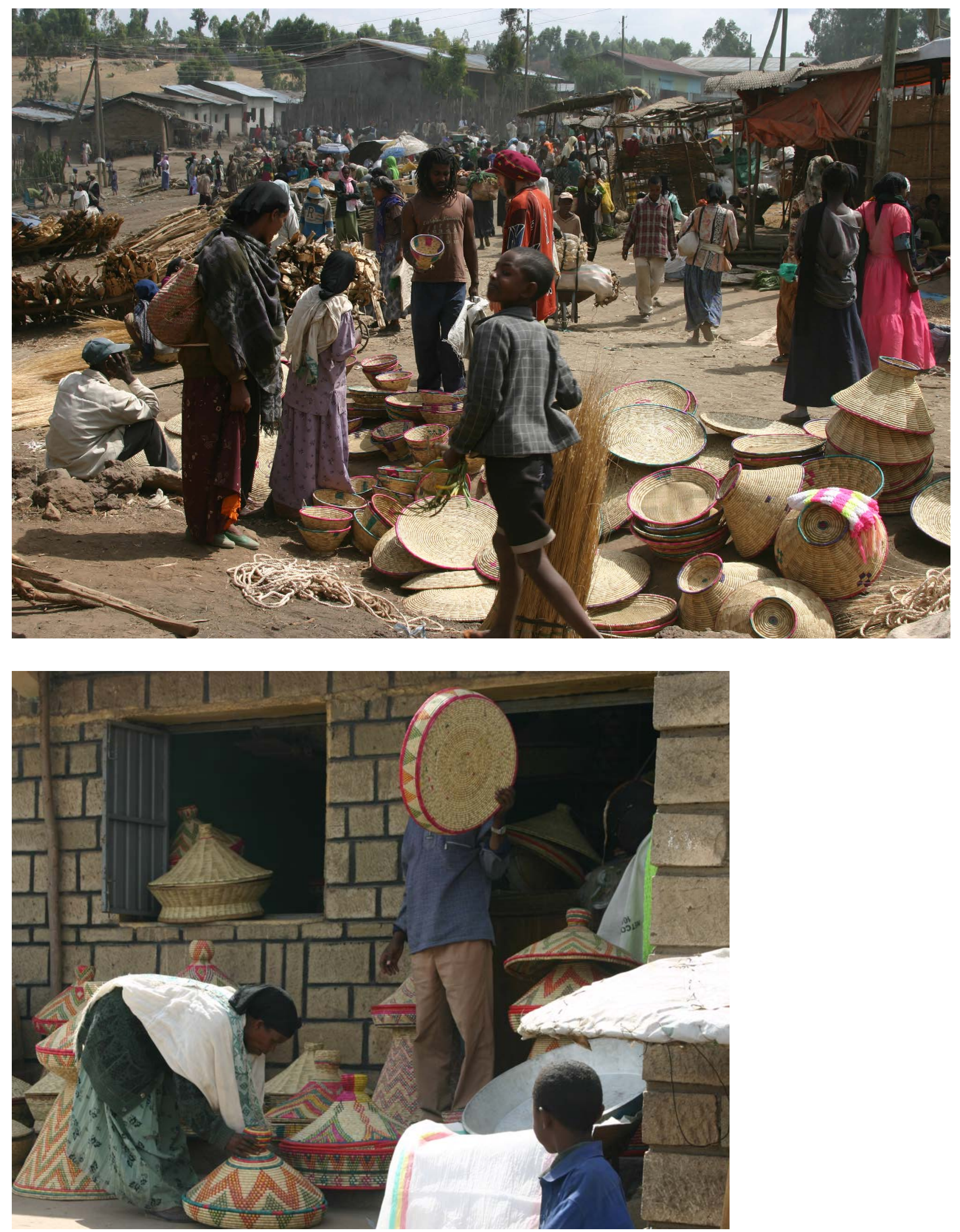

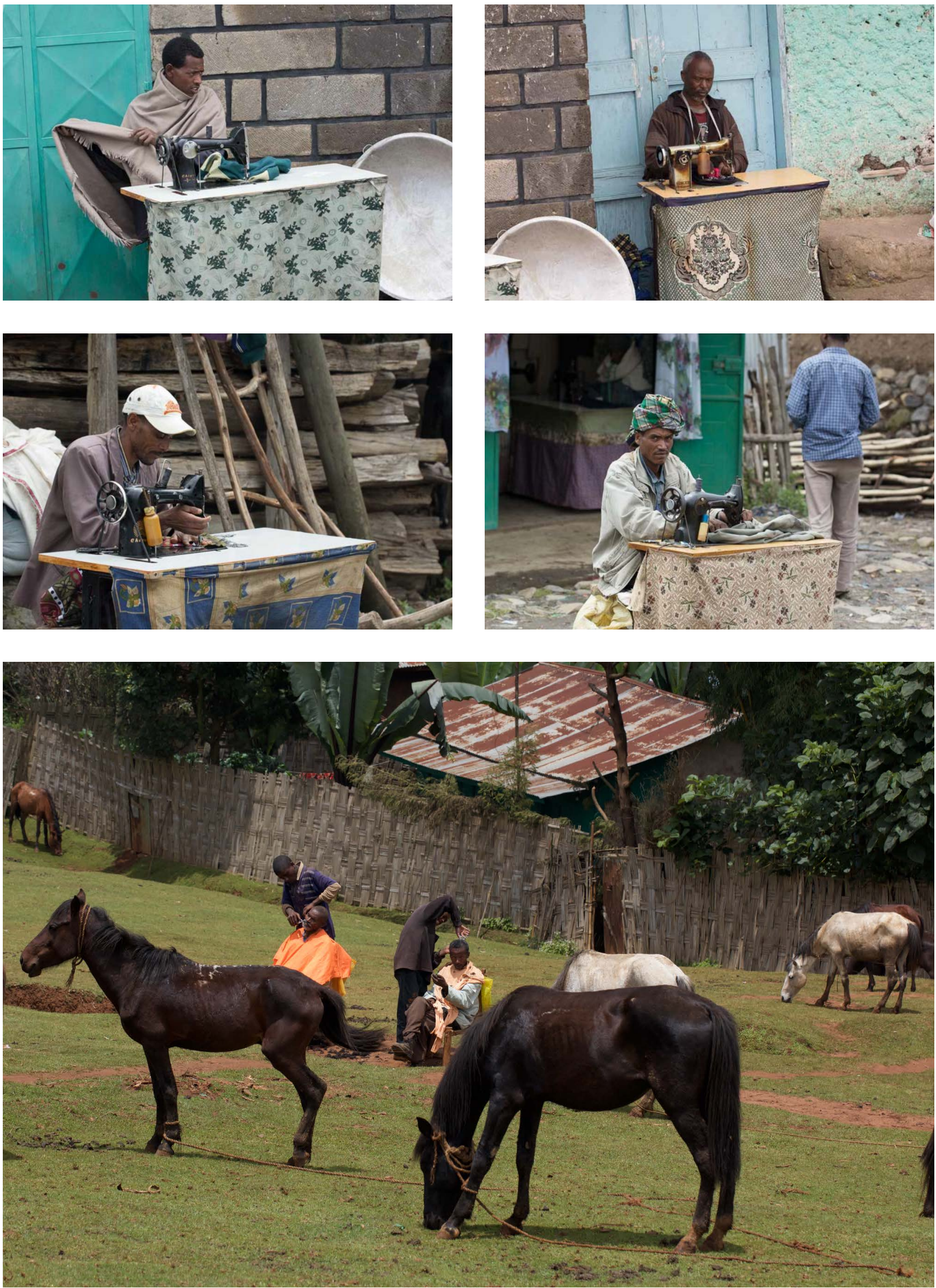

Rev. antropol. (São Paulo, Online) | v. 60 n. 3: 163-180 | USP, 2017 

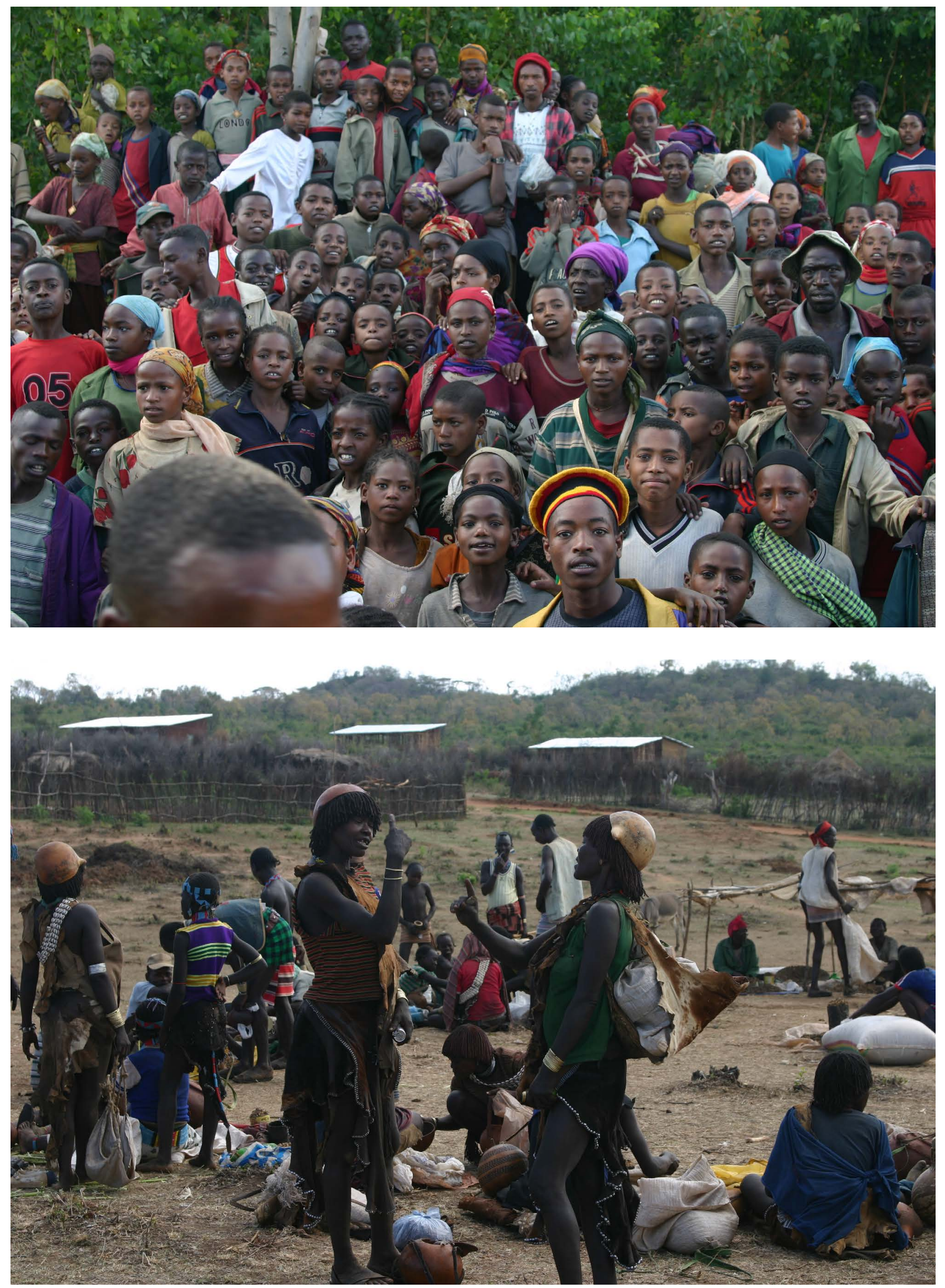

Rev. antropol. (São Paulo, Online) | v. 60 n. 3: 163-180 | USP, 2017 


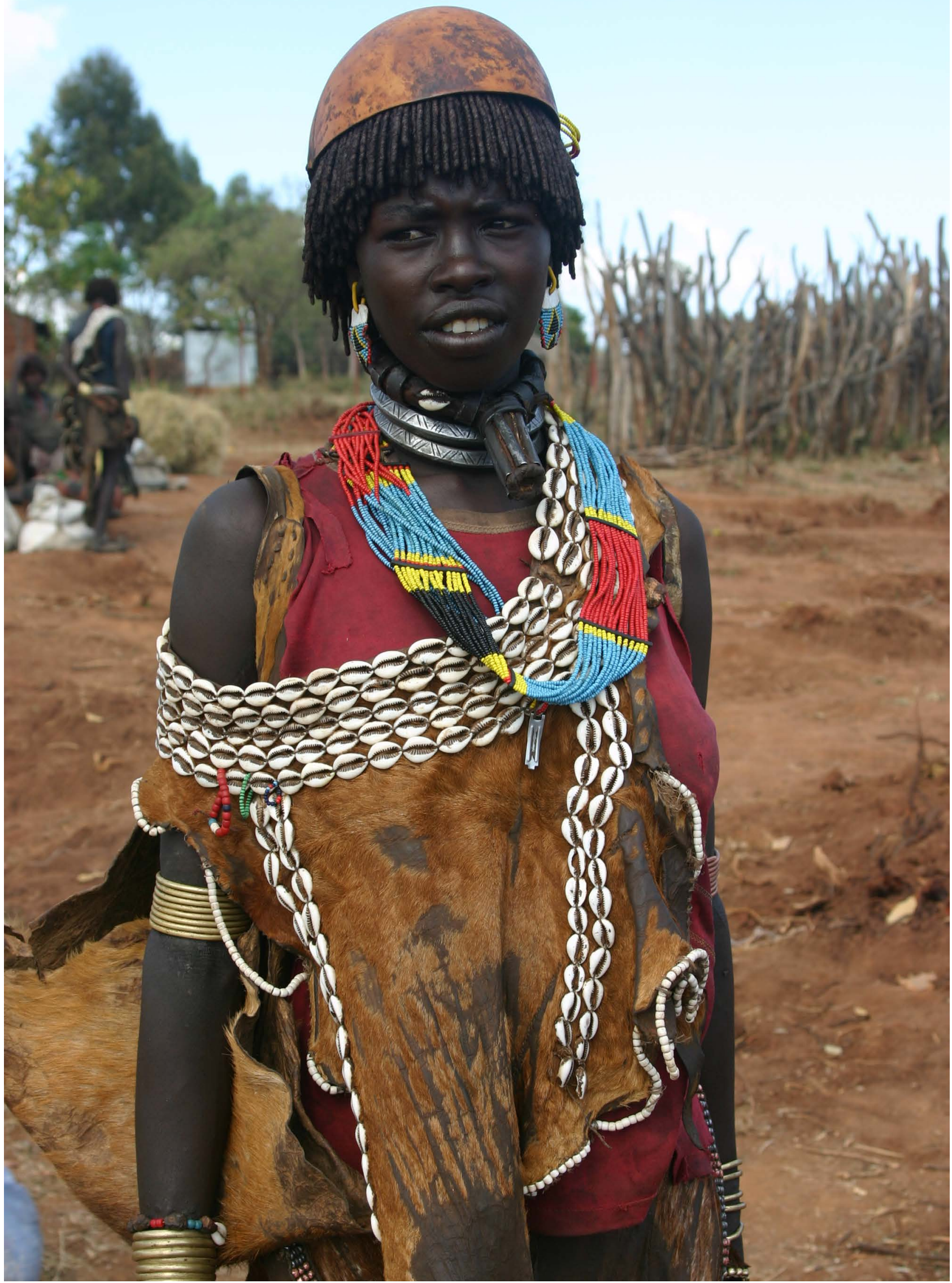

Rev. antropol. (São Paulo, Online) | v. 60 n. 3: 163-180 | USP, 2017 


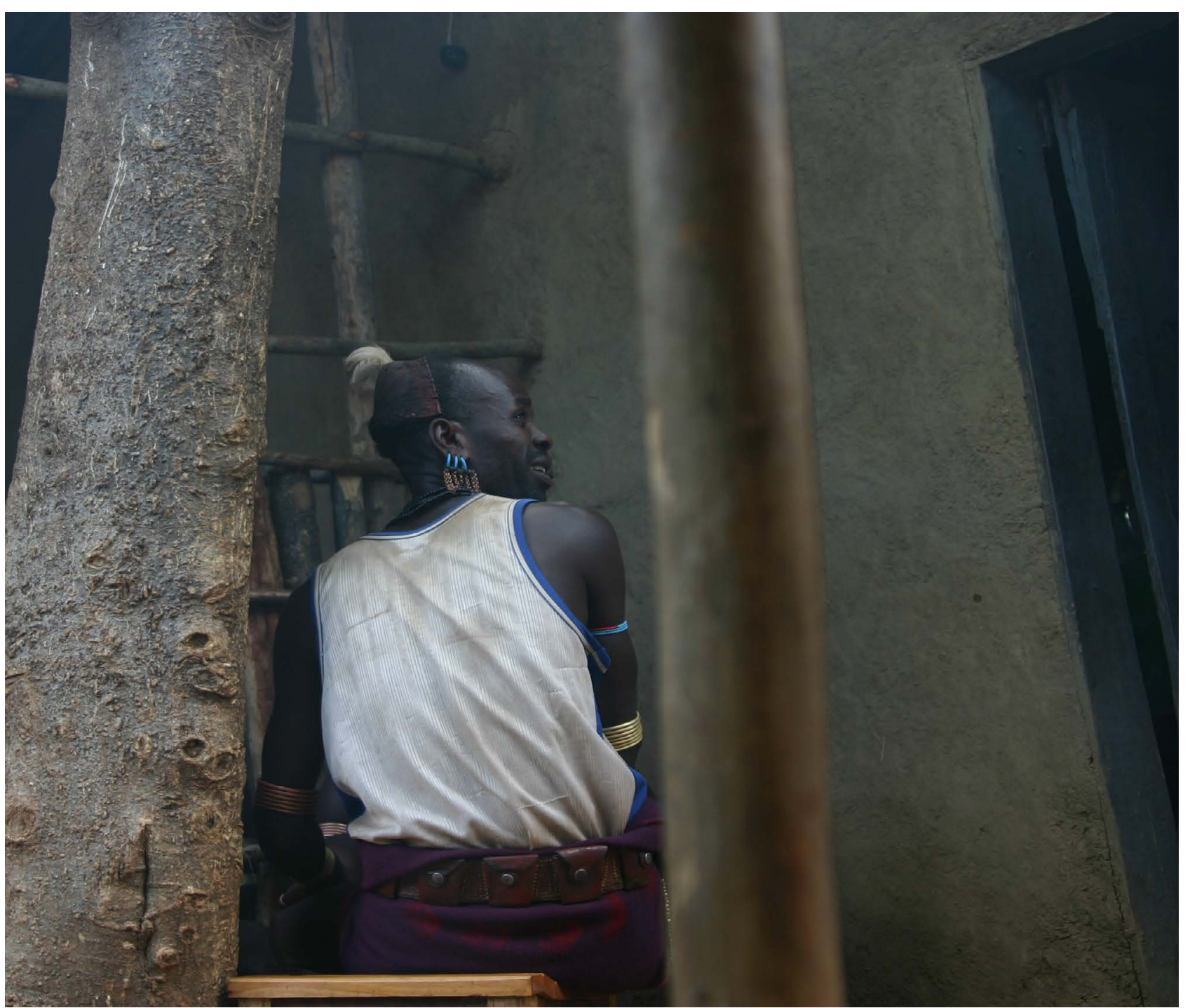



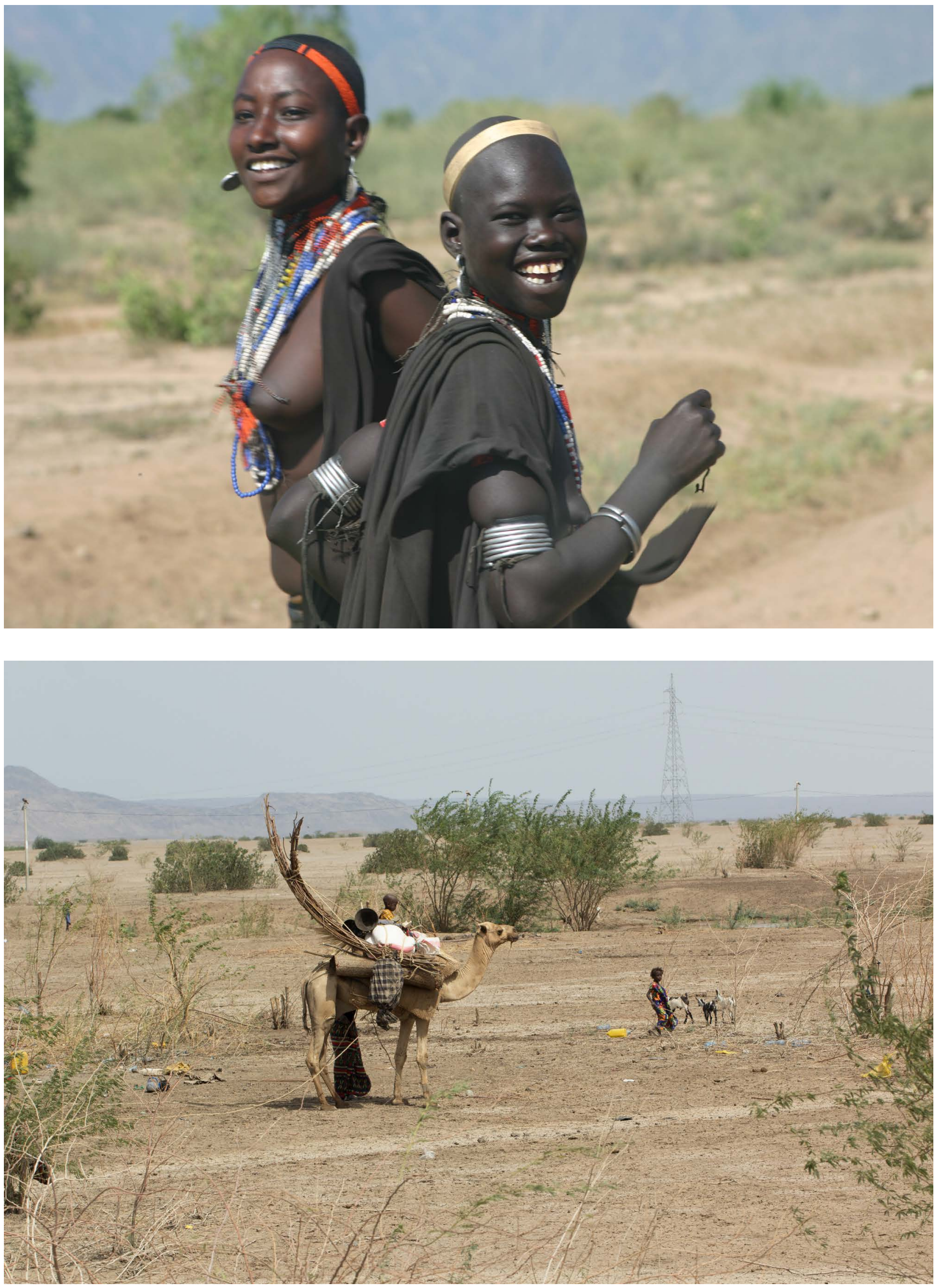

Rev. antropol. (São Paulo, Online) | v. 60 n. 3: 163-180 | USP, 2017 

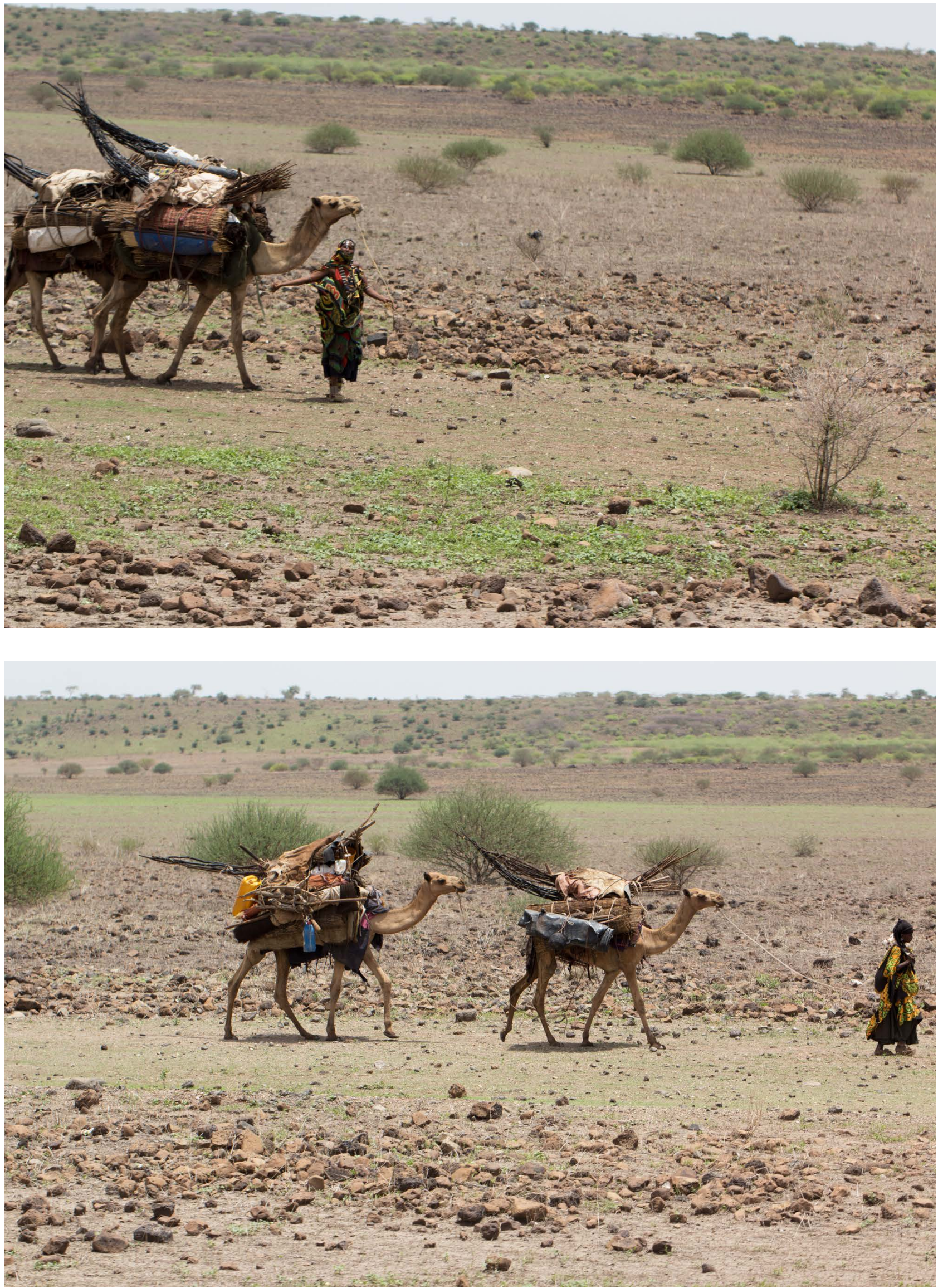

Rev. antropol. (São Paulo, Online) | v. 60 n. 3: 163-180 | USP, 2017 

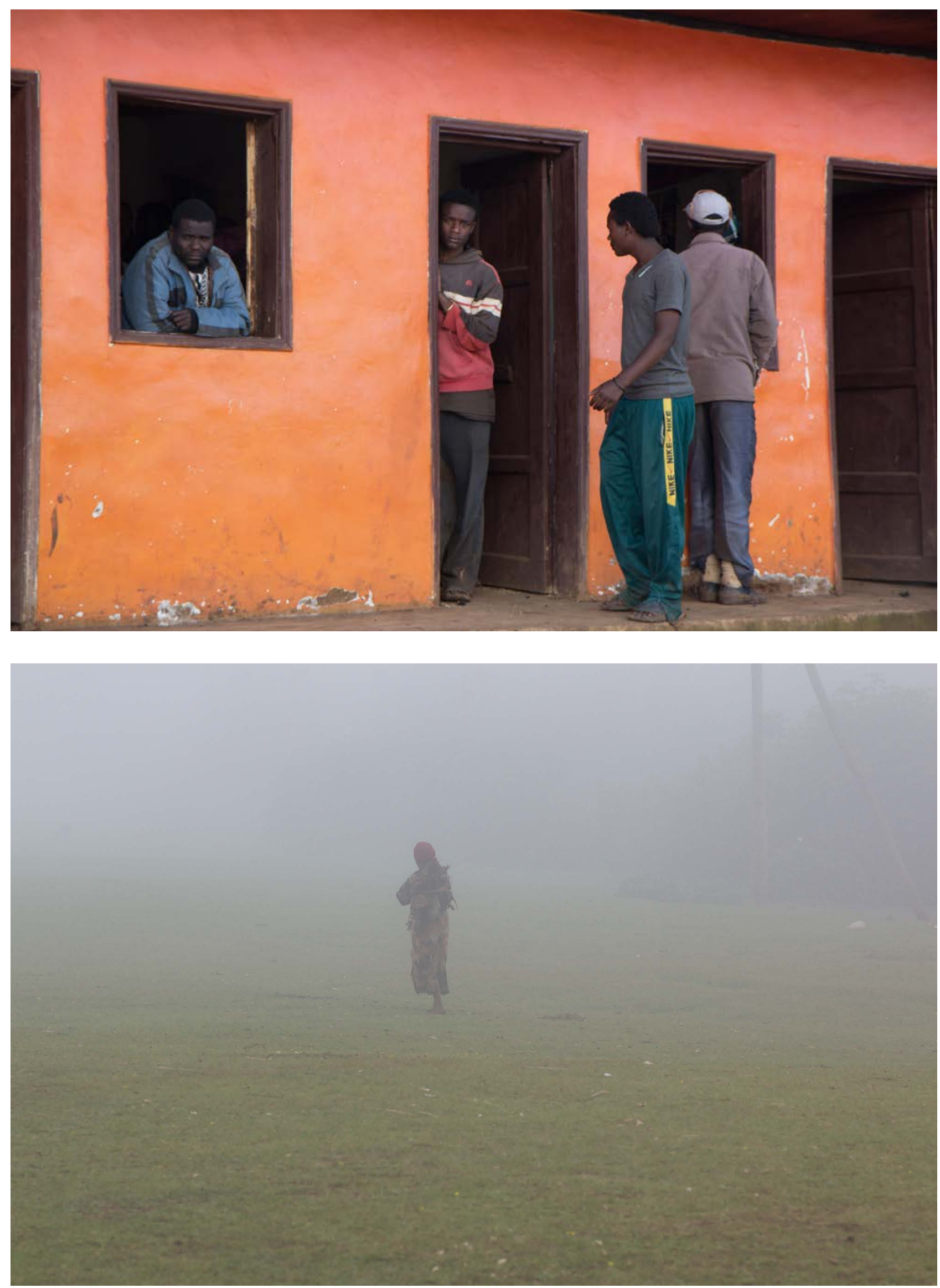


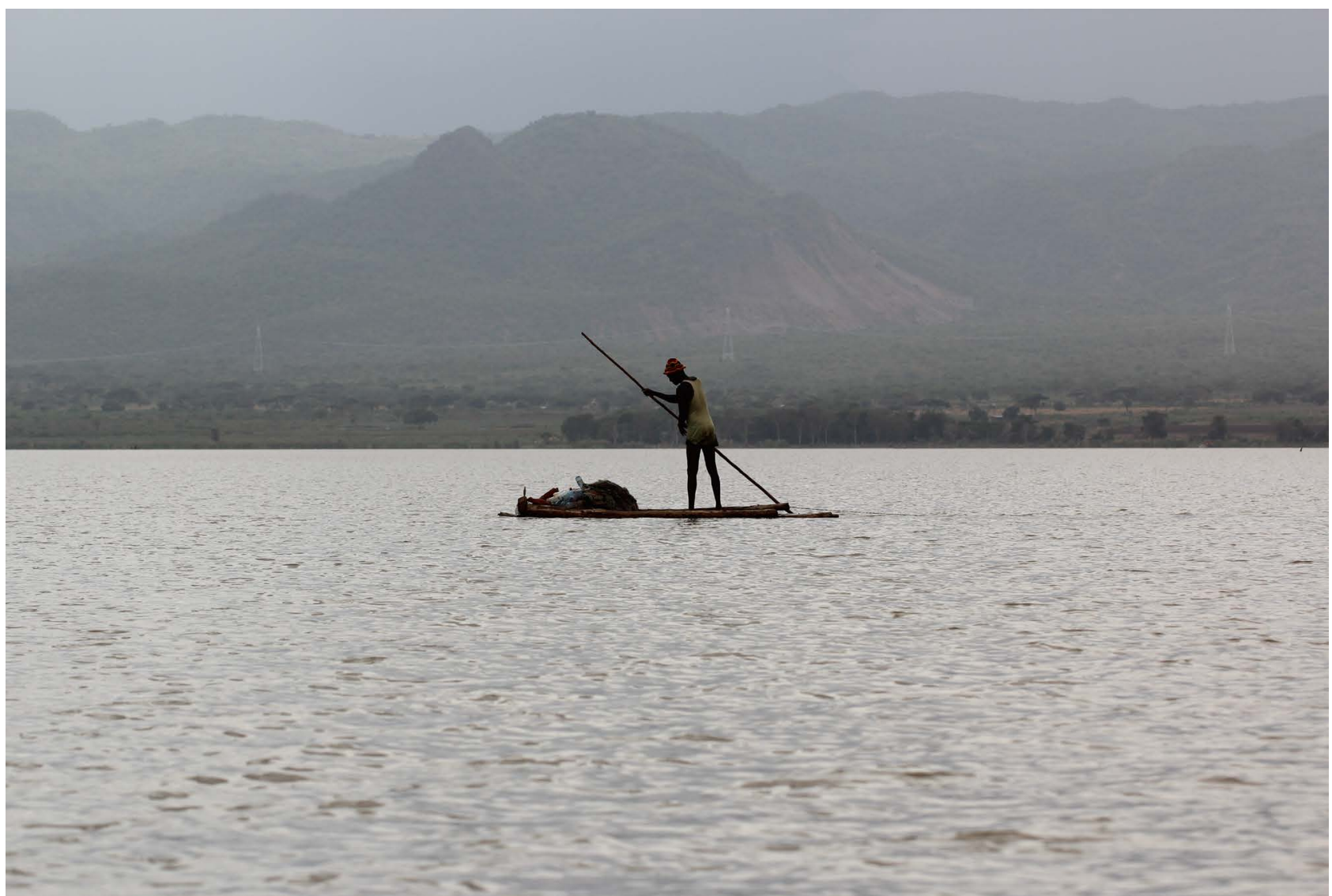

